
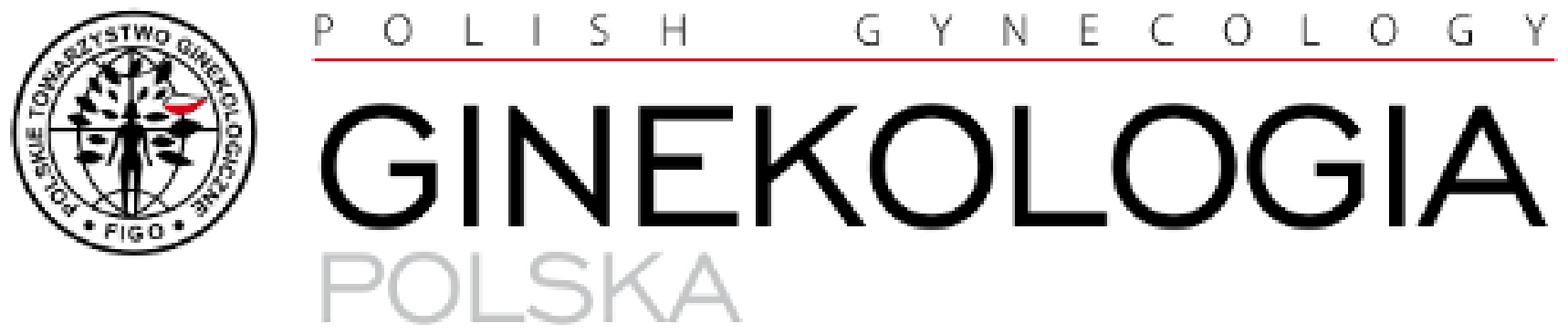

ORGAN POLSKIEGO TOWAAZYSTWA GINEKOLOGICZNEGO

THE OFFICIAL JOURNAL OF THE POLISH GYNECOLOGICAL SOCIETY

ISSN: 0017-0011

e-ISSN: $2543-6767$

\title{
Prenatal diagnosis of pure 1 p36 terminal deletion by chromosome microarry analysis - clinical report of 3 new cases and review of the literature
}

Authors: Tingting Song, Jiao Zheng, Yu Li, Jia Li, Fenfen Guo, Shuhua Zhao, Wei Zhang, Ying $\mathrm{Xu}$, Hong Yang

DOI: $10.5603 /$ GP.a2021.0173

Article type: Research paper

Submitted: $2021-03-16$

Accepted: $2021-06-12$

Published online: 2021-10-14

This article has been peer reviewed and published immediately upon acceptance.

It is an open access article, which means that it can be downloaded, printed, and distributed freely, provided the work is properly cited. 
Articles in "Ginekologia Polska" are listed in PubMed. 
Prenatal diagnosis of pure 1p36 terminal deletion by chromosome microarry analysis: clinical report of 3 new cases and review of the literature

Running title: Prenatal diagnosis of 1p36 terminal deletion

Tingting Song, Jiao Zheng, Yu Li, Jia Li, Fenfen Guo, Huashu Zhao, Wei Zhang, Ying

$\mathrm{Xu}^{*}$, Hong Yang*

Department of Obstetrics and Gynecology, the First Affiliated Hospital of Air Force

Medical University.

\section{Corresponding Author}

Ying Xu, Doctor, Department of Obstetrics and Gynecology, The First Affiliated Hospital of Air Force Medical University, Xi’an, 710032, Shanxi province, China

Tel: +86-029-84771653, Fax: +86-029-84771237

E-mail: xuyinglc@126.com

Hong Yang, Doctor, Department of Obstetrics and Gynecology, The First Affiliated

Hospital of Air Force Medical University, Xi'an, 710032, Shanxi province, China

Tel: +86-029-84771237, Fax: +86-029-84771237

E-mail: yanghongfck@163.com

\section{Abstract}

Objective: we objective to present the experience on prenatal diagnosis of 1p36 terminal deletion, and further delineated the fetal presentation of the syndrome. Materials and methods: This was a retrospective analysis of three new prenatal cases 
with pure 1p36 terminal deletion detected by chromosome microarray analysis (CMA) at a single Chinese medical center. We also reviewed 11 published prenatal cases with similar deletion sizes. Clinical data of all cases including indications for invasive testing, sonographic findings, maternal factors, and pregnancy outcomes were reviewed and analyzed. Results: Three new cases with pure 1p36 terminal deletion were prenatal diagnosed by CMA, the sizes of the deletion were $1.3 \mathrm{Mb}$, 5.0 Mb, and 4.9 Mb respectively. All cases were detected because of abnormal ultrasound findings, including central nervous system (CNS) abnormalities, congenital heart disease (CHD) and fetal growth restriction. Two pregnancies were terminated, and one was live-born but died three months after birth. Conclusions: The 1p36 terminal deletion results in many clinical manifestations, but the specificity of clinical features are not high. Prenatal sonographic findings such as CNS, CHD may act as suggestive signs of $1 \mathrm{p} 36$ deletion or other microdeletion/duplication syndromes.

Keywords: Prenatal diagnosis; 1p36 terminal deletion; Chromosomal microarray analysis; Prenatal ultrasound findings

\section{Introduction}

Chromosome 1p36 deletion syndrome (OMIM 607872) is the most common subtelomeric terminal deletion syndrome, with an estimated incidence of 1/5000 births ${ }^{[1]}$. The previous study showed that the deletion size and breakpoints varies widely from 1.5 Mb - >10 Mb, about 40\% of all breakpoints occur 3.0-5.0 Mb from the telomere, and $50 \%$ of individuals with 1 p36 deletion syndrome have a terminal deletion $^{[2]}$. The major clinical features of 1 p36 deletion syndrome patients characterized by a variety of generalized hypotonia, seizure, prenatal or postnatal growth restriction, severe developmental delays, facial features and $\mathrm{CHDs}^{[3,4}$, the patients may also show skeletal abnormalities, fetal akinesia, gastrointestinal malformations, cutis laxa, and biliary atresia ${ }^{[5-7]}$. Although 1p36 deletion syndrome was considered clinically recognizable, there was significant phenotypic variation among affected individuals, patients with this syndrome should undergo a 
multidisciplinary evaluation and receive comprehensive follow-up treatment.

The deletion sizes of about 40\% 1p36 terminal deletion patients are 3.0 - $5.0 \mathrm{Mb}$, so traditional cytogenetic techniques including karyotype analysis and fluorescence in situ hybridization (FISH) are insufficient good diagnostic tools. In recent years, CMA is increasingly used in clinical genetics both in the postnatal and prenatal settings, several studies have focused specifically on the use of CMA in prenatal diagnosis of fetuses with abnormal ultrasound findings ${ }^{[8,9]}$, so more and more microdeletions and microduplications including 1p36 deletion were identified. However, only a few prenatal identified cases have been reported, prenatal diagnosis and genetic counseling are challenging. Sarah Guterman et al. reported ten new cases and reviewed 22 prenatally diagnosed $\operatorname{cases}^{[10]}$, Xun Zhang et al. also reported ten new prenatal cases of 1 p36 deletion ${ }^{[11]}$, but not all cases with pure 1p36 terminal deletion in previous studies. Therefore, more prenatal cases are necessary to delineate the fetal manifestations of the syndrome. In our present study, we present three new 1p36 terminal deletion cases in which prenatal ultrasonography demonstrated fetal manifestations, objective to present the prenatal features associated with the terminal chromosomal deletion. In addition, we also gathered 11 published prenatal cases of the deletion size less than $5 \mathrm{Mb}$ and compared these new cases with the published data, further shed light on the genotypes and phenotypes.

\section{Materials and methods}

\section{Case selection}

This was a retrospective study, we reviewed three prenatal cases of 1p36 terminal deletion diagnosed at the First Affiliated Hospital of the Air Force Military Medical University, from January 2015 to August 2019. Only cases with pure 1 p36 terminal deletion were included. We also reviewed 11 published prenatal cases of 1 p36 terminal deletion with similar deletion sizes. Clinical data of all cases including maternal factors, sonographic findings, the indication for the invasive, duration of gestation at the time of diagnosis, and pregnancy outcomes were reviewed and analyzed.

\section{Genomic DNA preparation}


Amniotic fluid $(20 \mathrm{ml})$ was sampled by amniocentesis after obtaining informed consent from the parents. Genomic DNA was extracted from amniotic fluid (10 ml) by a QIAamp DNA Blood Mini Kit (Qiagen, Venlo, The Netherlands). Nanodrop 2000 (Thermo Fisher Scientific, Waltham, MA, USA) was used for detecting the concentration and quality of genomic DNA.

\section{CMA}

Cytoscan 750k array (Thermo Fisher Scientifc, Santa Clara, CA, USA) with an average resolution of $100 \mathrm{~kb}$ for copy number variations (CNVs) was used according to the standard manufacturer's protocol. The public Databases such as OMIM (http://www.ncbi.nlm.nih.gov/omim), DECIPHER (http://decipher.sanger.ac.uk/), ISCA (https://www.iscaconsortium.org/), and PubMed (http://www.ncbi.nlm.nih.gov/pubmed/) were used for the interpretation of the results and to analyze genotype-phenotype correlations.

\section{Results}

In this study, only prenatal cases with a pure terminal deletion were enrolled. Three cases of 1p36 terminal deletion were detected because of abnormal ultrasound findings including CNS abnormalities and CHDs. G-band karyotyping of them showed normal. CMA demonstrated a deletion of $1.3 \mathrm{Mb}$ between genomic positions 849,466 and 2,121,139 (hg19) at 1p36.33 including 32 OMIM genes in case 1 . A deletion of $5.0 \mathrm{Mb}$ and $4.9 \mathrm{Mb}$ were detected in case 2 and case 3 respectively, and 56 OMIM genes were included in the region. The detailed descriptions of the new cases and published cases were summarized in Table 1. CMA results were showed in figure 1.

We followed up all cases by telephone, case 1 and 3 decided to terminate the pregnancy and case 2 remain selected to continue the pregnancy after detail genetic counseling. Case 2 was born by cesarean section at 38th week of gestation with an Apgar score of five at $1 \mathrm{~min}$ and five at $5 \mathrm{~min}$, anoxia and respiratory weakness were observed, then the neonate was sent to the NICU for treatment. The case was observed to have hypertelorism, and deep-set ears, feeding difficulties, poor hearing, 
hypotonia, seizures and developmental delay. In addition, patent ductus arteriosus and patent foramen ovale were identified by postpartum echocardiography. Unfortunately, the case died three months after birth.

\section{Discussion}

Until now, few cases of prenatal diagnosis of pure 1p36 terminal deletion have been reported in the literature, especially those with a deletion less than $5 \mathrm{Mb}$, suggesting that some cases might have been underdiagnosed because of the low resolution karyotyping ${ }^{[12]}$. In recent years, with the wide application of genome-wide highresolution CMA in prenatal diagnosis, more and more microdeletion or microduplication syndromes are detected ${ }^{[13,14]}$. In the current study, we report three new cases of prenatal diagnosis of pure $1 p 36$ terminal deletion detected by CMA, and gathered 11 published prenatal cases of the deletion size within(less than) $5 \mathrm{Mb}$. We tried to identify the prenatal clinical manifestations and genotypephenotype relationship of pure 1 p36 terminal deletion.

It was noteworthy that CNS abnormalities are common ultrasonic manifestations of pure 1 p36 terminal deletion fetuses. In our new cases and the published cases one or more CNS abnormalities including ventriculomegaly, agenesis of the corpus callosum and cerebellar hypoplasia were observed in six of the fourteen cases. Prenatal ultrasonography revealed CNS abnormalities for fetuses with the deletion include ventriculomegaly, hydrocephalus, interhemispheric cyst, abnormal sylvian fossa, cerebellar hypoplasia and agenesis of the corpus callosum. The most common CNS abnormality in the prenatal ultrasonic findings was ventriculomegaly, four fetuses were detected with isolated ventriculomegaly or combined with other abnormalities. These 
findings suggest that CMA should be offered to fetuses with ventriculomegaly, regardless whether or not other structural abnormalities are associated. We also identified a case with agenesis of the corpus callosum that was rare in the literature. Our findings support that a variety of brain abnormalities including ventriculomegaly, hydrocephalus, and agenesis of the corpus callosum associated with 1 p36 deletion syndrome.

Congenital heart disease is also one of the most common clinical manifestations in prenatal echocardiography examination of fetuses with $1 p 36$ deletion. Shino Shimada et al. study showed that CHDs were observed in 69\%, patent ductus arteriosus and ventricular septal defects were the most frequently observed patterns ${ }^{4]}$, but not all CHDs were prenatally identified. Seven cases were identified with various cardiac anomalies such as ventricular septal defect, noncompaction of ventricular myocardium, double outlet right ventricle, pulmonary valve stenosis in our new and the published cases. In our case 3, noncompaction of ventricular myocardium was identified by prenatal echocardiography, this was consistent with the previous study. In addition, there were many reports that reveal the association between ebstein anomaly and $1 p 36$ terminal deletion $^{[15-17]}$. In the prenatal study, three fetuses with ebstein anomaly were detected, further provide the basis for $1 p 36$ terminal deletion prenatal diagnosis. Therefore, the finding of cardiac abnormalities poses a high risk of 1 p36 terminal deletion for the fetus. The ventricular septal defect was detected at 28th week of pregnancy in case 1 , and CMA revealed a $1.3 \mathrm{Mb}$ deletion in 1p36 terminal. To our best knowledge, this was the smallest deletion found before delivery, but 32 OMIM genes were included and many of them such as GNB1, PRKCZ, GABRD are well defined. Previously 
studies suggest that the gene GNB1 implicated in neurological development ${ }^{[18]}$. The gene $P R K C Z$ was thought to be necessary for regulating axonal differentiation and had been implicated in a variety of processes including cardiac muscle function ${ }^{[19,20]}$. The gene GABRD encodes the subunit of the GABAA receptors, plays an important role in mammalian brain development, and haploinsufficiency may be responsible for neurologic features ${ }^{[21]}$. Previous studies showed that even a small deletion at the 1p36 terminal might lead to phenotypic alteration ${ }^{[22]}$. Considering the possible clinical manifestations such as developmental delay, mental retardation and CHDs, the couple decided to terminate the pregnancy after detailed genetic counseling. Characterization of the prenatal case with small deletion is helpful for narrowing critical intervals of 1 p36 deletion syndrome.

The prenatal diagnosis of 1 p36 terminal deletion is a challenge because of the variability clinical manifestations and depends largely on the gestational age when the diagnosis was made. Though CNS abnormalities and cardiac abnormalities could be the most common features in prenatal 1p36 terminal deletion cases, the prenatal ultrasound features of 1 p36 terminal deletion remain nonspecific. When cases with ultrasound findings such as congenital heart defects, ventriculomegaly, agenesis of the corpus callosum, a clinical suspicion of $1 p 36$ terminal deletion or other microdeletion/microduplication syndromes should be considered. In addition, isolated abnormalities such as ventriculomegaly may not attract the attention of pregnant women, so the best time for invasive prenatal diagnosis was missed. We suggest that cases with ultrasound findings such as CHDs, ventriculomegaly, agenesis of the corpus callosum should alert clinicians to the possibility of 
chromosome 1p36 deletion syndrome or other microdeletion/duplication syndromes.

In conclusion, CMA is an effective method for the precise diagnosis of 1 p36 terminal deletion. We summarized the characteristics and prenatal clinical findings of fetuses with pure 1p36 terminal deletion, aim to emphasize the importance of CMA in detecting chromosomal abnormalities and provide a basis for prenatal diagnosis. Since 1p36 terminal deletion is associated with a poor prognosis in general and severe intellectual disability in particular, the prenatal diagnosis of this condition may help parents to decide whether to continue or to terminate the pregnancy.

\section{Conflict of interest}

All authors declare no conflict of interest.

\section{Funding}

This work was supported by the [Key Research and Development Program of Shaanxi Province] under Grant [2019ZDLSF01-06]; [Key Research and Development Program of Shaanxi Province, Joint University Program-- General items] under Grant [2020GXLH-Y-009]; [Hospital discipline booster program of the First Affiliated Hospital of the air force Medical University] under Grant [XJZT18MJ53]; [Key Project of Shaanxi Province--Social Development Field] under Grant [2017ZDXMSF-037]; and [Military Youth Training Program] under Grant [16QNP112]..

\section{Acknowledgments}

We thank the family for their participation in the study and the support of funding.

\section{Reference}

[1] Jordan, V. K., H. P. Zaveri and D. A. Scott. 1p36 deletion syndrome: an update. Appl Clin Genet, 2015, 8,189-200. doi:10.2147/TACG.S65698.

[2] Guterman, S, C. Beneteau, S. Redon, et al. Prenatal findings in 1 p36 deletion syndrome: New cases and a literature review. Prenat 
Diagn, 2019, 39(10),871-882. doi:10.1002/pd.5498.

[3] Greco, M, P. Ferrara, G. Farello, et al. Electroclinical features of epilepsy associated with 1p36 deletion syndrome: A review. Epilepsy Res, 2018, 139, 92-101. doi:10.1016/j.eplepsyres.2017.11.016.

[4] Shimada, S, K. Shimojima, N. Okamoto, et al. Microarray analysis of 50 patients reveals the critical chromosomal regions responsible for $1 p 36$ deletion syndrome-related complications. Brain Dev, 2015, 37(5), 515-526. doi:10.1016/j.braindev.2014.08.002.

[5] Toshimitsu, M, S. Nagaoka, S. Kobori, et al. Exome-First Approach in Fetal Akinesia Reveals Chromosome 1p36 Deletion Syndrome. Case Rep Obstet Gynecol, 2019, 6753184. doi:10.1155/2019/6753184.

[6] Zhang, Z, J. Wang, N. Li, et al. Cutis laxa in a patient with 1p36 deletion syndrome. J Dermatol, 2018, 45(7),871-873. doi:10.1111/1346-8138.14311.

[7] Chawla, V, M. R. Anagnost, A. E. Eldemerdash, et al. A Novel Case of Biliary Atresia in a Premature Neonate With 1p36 Deletion Syndrome. J Investig Med High Impact Case Rep, 2018, 6, 2324709618790613. doi:10.1177/2324709618790613.

[8] Hu, T, Z. Zhang, J. Wang, et al. Prenatal diagnosis of chromosomal aberrations by chromosomal microarray analysis in fetuses with ultrasound anomalies in the urinary system. Prenat Diagn, 2019, 39(12),1096-1106. doi:10.1002/pd.5550.

[9] Song, T, S. Wan, Y. Li, et al. Detection of copy number variants using chromosomal microarray analysis for the prenatal diagnosis of congenital heart defects with normal karyotype. J Clin Lab Anal, 2019, 33(1),e22630. doi:10.1002/jcla.22630.

[10] Guterman, S, C. Beneteau, S. Redon, et al. Prenatal findings in 1p36 deletion syndrome: New cases and a literature review. Prenat 
Diagn, 2019, 39(10),871-882. doi:10.1002/pd.5498.

[11] Zhang, X, P. He, J. Han, et al. Prenatal detection of 1p36 deletion syndrome: ultrasound findings and microarray testing results. J Matern Fetal Neonatal Med,,2019, 1-121. doi:10.1080/14767058.2019.1660764.

[12] Campeau, P. M, N. Ah Mew, L. Cartier, K. L et al. Prenatal diagnosis of monosomy 1p36: a focus on brain abnormalities and a review of the literature. Am J Med Genet A, 2008, 146A(23),30623069. doi:10.1002/ajmg.a.32563.

[13] Chang, Q, Y. Yang, Y. Peng, et al. Prenatal detection of chromosomal abnormalities and copy number variants in fetuses with ventriculomegaly. Eur J Paediatr Neurol. 2020, doi:10.1016/j.ejpn.2020.01.016.

[14] Fu, F, Q. Deng, T. Y. Lei, et al. Clinical application of SNP array analysis in fetuses with ventricular septal defects and normal karyotypes. Arch Gynecol Obstet, 2017, 296(5),929-940. doi:10.1007/s00404-017-4518-2.

[15] Battaglia, A, H. E. Hoyme, B. Dallapiccola, et al. Further delineation of deletion 1 p36 syndrome in 60 patients: a recognizable phenotype and common cause of developmental delay and mental retardation. Pediatrics, 2008, 121(2),404-410. doi:10.1542/peds.2007-0929.

[16] Digilio, M. C, L. Bernardini, F. Lepri, et al. Ebstein anomaly: Genetic heterogeneity and association with microdeletions 1 p36 and 8p23.1. Am J Med Genet A, 2011, 155A(9),2196-2202. doi:10.1002/ajmg.a.34131.

[17] Redon, R, M. Rio, S. G. Gregory, et al. Tiling path resolution mapping of constitutional 1p36 deletions by array-CGH: contiguous gene deletion or "deletion with positional effect" syndrome? J Med 
Genet, 2005, 42(2),166-171. doi:10.1136/jmg.2004.023861.

[18] Hemati, P, A. Revah-Politi, H. Bassan, S. et al. Refining the phenotype associated with GNB1 mutations: Clinical data on 18 newly identified patients and review of the literature. Am J Med Genet A, 2018, 176(11),2259-2275. doi:10.1002/ajmg.a.40472.

[19] Sentex, E, X. Wang, X. Liu, A. et al. Expression of protein kinase $C$ isoforms in cardiac hypertrophy and heart failure due to volume overload. Can J Physiol Pharmacol, 2006, 84(2),227-238. doi:10.1139/y05-120.

[20] Wu, S. C. and R. J. Solaro. Protein kinase C zeta. A novel regulator of both phosphorylation and de-phosphorylation of cardiac sarcomeric proteins. J Biol Chem, 2007, 282(42),30691-30698. doi:10.1074/jbc.M703670200.

[21] Gilsoul, M, T. Grisar, A. V. Delgado-Escueta, L. et al. Subtle Brain Developmental Abnormalities in the Pathogenesis of Juvenile Myoclonic Epilepsy. Front Cell Neurosci, 2019, 13,433. doi:10.3389/fncel.2019.00433.

[22] Rosenfeld, J. A, J. A. Crolla, S. Tomkins, et al. Refinement of causative genes in monosomy 1p36 through clinical and molecular cytogenetic characterization of small interstitial deletions. Am J Med Genet A, 2010, 152A(8),1951-1959. doi:10.1002/ajmg.a.33516. 


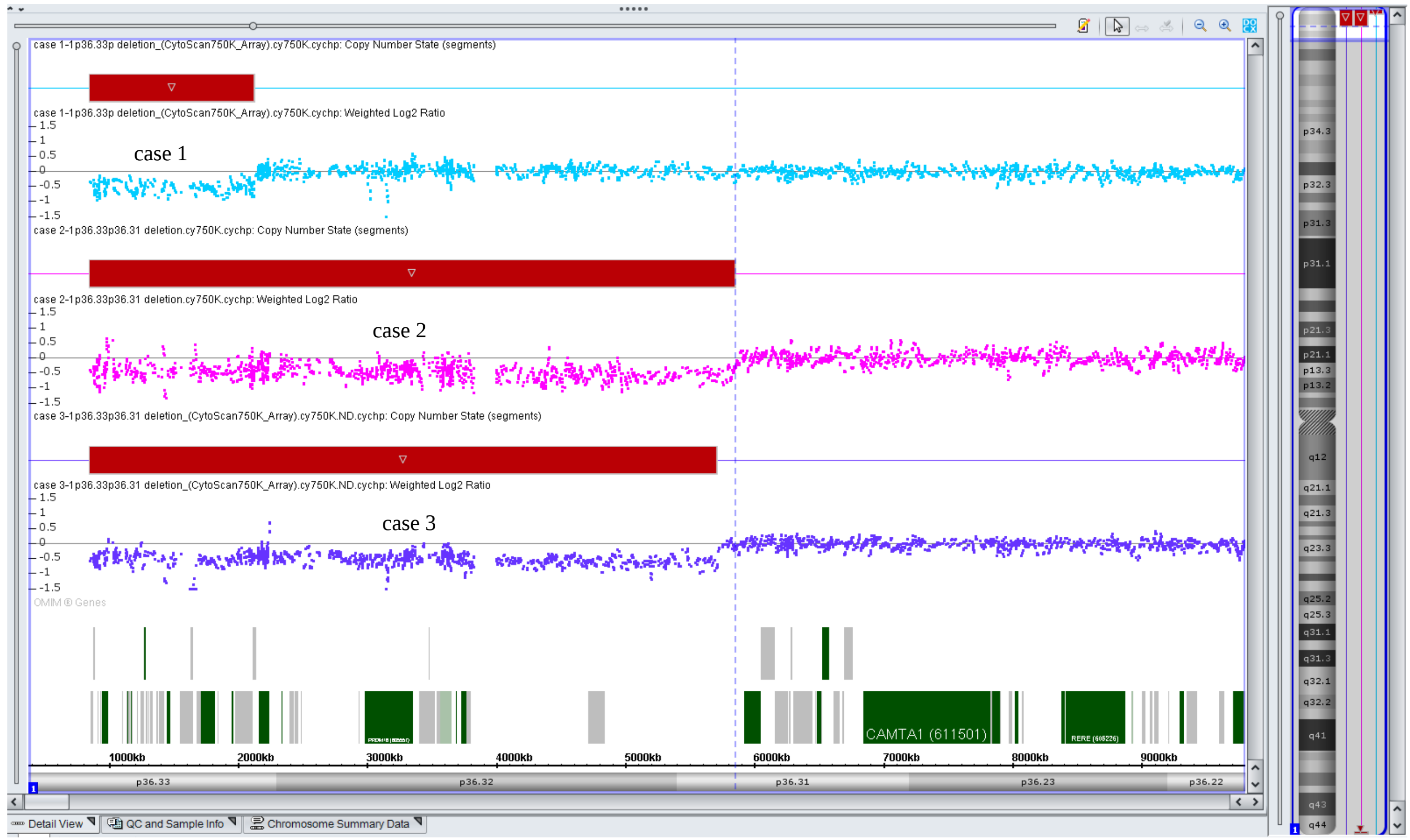

Fig 1. The CMA profile of the 1p36 microdeletions were represented by the bold red line. OMIM genes were listed at the bottom, dark green can be diseasecausing. 39 OMIM genes were involved in the deletion region of case 1, 56 OMIM genes were involved in the deletion region of case 2 and 3. 
Table 1. Prenatal findings in fetuses with 1p36 terminal deletion in our study and literature

\begin{tabular}{|c|c|c|c|c|c|c|c|c|}
\hline Case & $\begin{array}{l}\text { Maternal } \\
\text { age (years) }\end{array}$ & $\begin{array}{l}\text { Gestation } \\
(\mathrm{w}+\mathrm{d})\end{array}$ & Ultrasound finding & G-band & CMA results & $\begin{array}{l}\text { Size } \\
(\mathrm{Mb})\end{array}$ & $\begin{array}{l}\text { Inheritan } \\
\text { ce }\end{array}$ & $\begin{array}{c}\text { Pregnancy } \\
\text { outcome }\end{array}$ \\
\hline 1 & 32 & $32+4$ & VSD & 46, XX & arr[GRCh37] 1p36.33(849,466_2,121,139)x1 & 1.3 & Unknown & TOP \\
\hline 2 & 33 & $23+1$ & ACC, polyhydramnios & 46, XX & $\begin{array}{c}\operatorname{arr}[\text { GRCh37] } \\
\text { 1p36.33p36.31(849,466_5,851,366)x1 }\end{array}$ & 5.0 & De novo & Born, death \\
\hline 3 & 29 & $31+1$ & $\begin{array}{l}\text { VMG, subependymal } \\
\text { cyst, NVM }\end{array}$ & 46, XY & $\begin{array}{c}\text { arr[GRCh37] } \\
\text { 1p36.33p36.31(849,466_5,708,006)x1 }\end{array}$ & 4.9 & Unknown & TOP \\
\hline $\begin{array}{l}\text { Sarah } \\
\text { Guterman et } \\
\quad \text { al } 1\end{array}$ & 21 & 13 & $\begin{array}{l}\text { Interhemispheric cyst, NT } \\
4.8 \mathrm{~mm} \text {, subcutaneous } \\
\text { edema }\end{array}$ & 46, XY & $\begin{array}{c}\operatorname{arr}[\text { GRCh37]1p36.33p36.32(759,762_2,879,96 } \\
\text { 3)x1 }\end{array}$ & 2.1 & $\begin{array}{l}\text { Unknow } \\
\mathrm{n}\end{array}$ & TOP \\
\hline $\begin{array}{c}\text { Sarah } \\
\text { Guterman et } \\
\text { al } 4\end{array}$ & 36 & 13 & Retrognathia & 46, XX & $\begin{array}{c}\operatorname{arr}[\text { GRCh37] } \\
\text { 1p36.33p36.2(779,727_4,859,438)x1 }\end{array}$ & 4 & De novo & TOP \\
\hline $\begin{array}{l}\text { Sarah } \\
\text { Guterman et } \\
\quad \text { al } 8\end{array}$ & 30 & 26 & $\begin{array}{c}\text { Bilateral VMG, abnormal } \\
\text { sylvian fossa, cerebellar } \\
\text { hypoplasia }\end{array}$ & $46, X Y$ & arr[GRCh37] 1p36.33(834101_2225782)x1 & 1.4 & De novo & TOP \\
\hline $\begin{array}{l}\text { Xun Zhang } \\
\text { et al } 3\end{array}$ & 45 & 11 & NT: $1.4 \mathrm{~mm}$ & 46, XY & $\begin{array}{c}\operatorname{arr}[G R C h 37] 1 p 36.33 p 36.32\left(849,466 \_2,516,03\right. \\
\text { 1)x1 }\end{array}$ & 1.7 & De novo & TOP \\
\hline $\begin{array}{l}\text { Xun Zhang } \\
\text { et al } 4\end{array}$ & 30 & 17 & $\begin{array}{l}\text { NT: } 1.7 \mathrm{~mm} \text {, cfDNA: } \\
\text { high risk for } 1 \mathrm{p}^{-}\end{array}$ & 46, XX & $\begin{array}{c}\operatorname{arr}[\text { GRCh37]1p36.33p36.31(849,466_6,374,40 } \\
7) \times 1\end{array}$ & 5.5 & De novo & TOP \\
\hline $\begin{array}{l}\text { Xun Zhang } \\
\text { et al } 5\end{array}$ & 27 & 22 & Ebstein anomaly & $46, \mathrm{XX}$ & $\begin{array}{c}\operatorname{arr}[\text { GRCh37]1p36.33p36.31(849,466_6,927,02 } \\
6) \times 1\end{array}$ & 6.1 & De novo & TOP \\
\hline $\begin{array}{l}\text { Xun Zhang } \\
\text { et al } 6\end{array}$ & 30 & 22 & DORV, PVS, VSD & 46, XX & $\begin{array}{c}\operatorname{arr}[\text { GRCh37]1p36.33p36.32(849,466_5,383,95 } \\
6) \times 1\end{array}$ & 4.5 & De novo & TOP \\
\hline $\begin{array}{l}\text { Xun Zhang } \\
\text { et al } 7\end{array}$ & 30 & 23 & Ebstein anomaly,VSD & 46, XY & $\begin{array}{c}\operatorname{arr}[\text { GRCh37]1p36.32p36.22(1,397,489_3,628,0 } \\
23) \times 1\end{array}$ & 2.3 & De novo & TOP \\
\hline
\end{tabular}




\begin{tabular}{|c|c|c|c|c|c|c|c|c|}
\hline $\begin{array}{l}\text { Xun Zhang } \\
\text { et al } 8\end{array}$ & 31 & 30 & Bilateral VMG (13mm) & 46, XY & $\begin{array}{c}\operatorname{arr}[G R C h 37] 1 p 36.33 p 36.31\left(849,466 \_6,435,58\right. \\
3) \times 1\end{array}$ & 5.6 & De novo & $\begin{array}{l}\text { still born, } \\
\text { death after } \\
\text { report in } \\
\text { reduced fetal } \\
\text { movement }\end{array}$ \\
\hline $\begin{array}{l}\text { Masatake } \\
\text { Toshimitsu } \\
\text { et al }\end{array}$ & 28 & $32+5$ & $\begin{array}{l}\text { Vascular ring, Ebstein’s } \\
\text { anomaly, VSD, and } \\
\text { single umbilical artery, } \\
\text { polyhydramnios, } \\
\text { FGR,VMG,CPCs }\end{array}$ & NA & $\begin{array}{c}\text { arr[GRCh37] } \\
\text { [hg]1p36.33p36.32(849466_3347420)x1 }\end{array}$ & 3 & De novo & $\begin{array}{l}\text { died within } 2 \mathrm{~h} \\
\text { after birth due } \\
\text { to respiratory } \\
\text { failure }\end{array}$ \\
\hline $\begin{array}{l}\text { Fang Fu et } \\
\text { al }\end{array}$ & NA & NA & VSD, DORV, PS & NA & $\begin{array}{c}\operatorname{arr}[\text { GRCh37][hg]1p36.33p36.32 } \\
\left(849,466 \_5,383,956\right) \times 1\end{array}$ & 4.5 & De novo & NA \\
\hline
\end{tabular}

Abbreviations: VSD, ventricular septal defect; ACC, agenesis of the corpus callosum; NVM, noncompaction of ventricular myocardium; TOP, Termination of pregnancy; AMA, advance maternal age; cfDNA, cell-free DNA; DORV, double outlet right ventricle; NA, not available; NT, nuchal translucency; PVS, Pulmonary valve stenosis; PS, Pulmonary stenosis; TOP, termination of pregnancy; VMG, ventriculomegaly; CPCs, choroid plexus cysts; FGR, fetal growth restriction; 